\title{
Análise de limitações e possibilidades para as pesquisas sobre políticas educacionais, considerando as abordagens positivista, fenomenológica e materialista dialética
}

\section{Analyzing the limitations and possibilities of education policy research under the positivist, phenomenological and dialectical materialistic approaches}

\section{Análisis de las limitaciones y posibilidades de las investigaciones en política educacional, considerando los abordajes positivista, fenomenológico y materialista dialéctico}

\author{
Giselle Abreu de Oliveira* \\ Gabriel Humberto Muñoz Palafox**
}

\begin{abstract}
Resumo: O presente artigo objetiva discutir aspectos relacionados à construção de pesquisas sobre políticas educacionais, tendo como ponto de partida três categorias de Tello (2012): perspectiva epistemológica, posicionamento epistemológico e enfoque epistemetodológico. Consideramos ainda as contribuições de Ball e Mainardes (2011), Lima (2010), Alves-Mazzotti (2003), Masson (2013), dentre outros, para analisarmos, no contexto do materialismo dialético, o impacto das abordagens positivista, materialista dialética e fenomenológica - essa última analisada especialmente quanto às pesquisas qualitativas. Com isso, buscamos compreender a natureza epistemológica de tais abordagens, bem como suas possibilidades e limitações para o processo de produção do conhecimento científico, além de contribuir para a consolidação do campo de estudos sobre políticas educacionais.
\end{abstract}

Palavras-chave: Epistemologias. Metodologias. Políticas públicas.

Abstract: This article aims to instigate discussions about the construction of educational research for policy and practices. This will be done considering three different categories: epistemological perspective, epistemological positioning and

* Pedagoga na Universidade Federal do Triângulo Mineiro (UFTM). Mestranda em Educação pela Universidade Federal de Uberlândia (UFU). E-mail: < gisellejcabreu@hotmail.com>

** Professor da Universidade Federal de Uberlândia (UFU). E-mail: <gabmpalafox@hotmail.com> 
epistemethodological approach by Tello (2012). Moreover, this article will consider the contributions of Mainardes and Ball (2011), Lima (2010), Alves-Mazzotti (2003), Masson (2013), among others, in order to analyze the context of dialectical materialism, the impact of positivist approaches, phenomenological and materialist dialectics. The latter especially analyzed with regard to qualitative research. In addition, we seek to understand the epistemological nature of such approaches, considering their possibilities and limitations to the process of scientific knowledge production, as well as to contribute to the field of studies on educational policies consolidation.

Keywords: Epistemologies. Methodologies. Educational policies.

Resumen: Este trabajo tiene como objetivo discutir aspectos relacionados con la construcción de la investigación en política educativa, tomando como punto de partida tres categorías de Tello (2012): perspectiva epistemológica, posicionamiento epistemológico y epistemetodología. También se consideran los aportes de Ball y Mainardes (2011), Lima (2010), Alves-Mazzotti (2003), Masson (2013), entre otros, para analizar, en el contexto del materialismo dialéctico, el impacto de los enfoques positivista, materialista dialéctico y fenomenológico, esta última analizada especialmente desde las investigaciones cualitativas. Así, tratamos de comprender la naturaleza epistemológica de estos enfoques, así como sus posibilidades y limitaciones en el proceso de producción de conocimiento científico, y así contribuir a la consolidación de los estudios de campo sobre las políticas educativas.

Palabras clave: Epistemologías. Metodologías. Políticas Públicas.

\section{Introdução}

A ciência moderna, constituída por meio da revolução científica do século XVI e desenvolvida nos séculos seguintes - basicamente no domínio das ciências da natureza -, estendeu seu modelo de racionalidade às ciências humanas e sociais a partir do século XIX e contribuiu para que as premissas do método científico positivista fossem consideradas insuficientes para responder aos questionamentos relacionados às peculiaridades da vida em sociedade. Dessa forma, o século XIX foi marcado pela presença de intelectuais das ciências sociais e humanas que questionaram tais premissas no intuito de ampliar os horizontes do conhecimento científico a respeito do próprio ser humano, da cultura e da vida cotidiana.

Até então, as pesquisas se fundamentavam em um tipo de lógica de pensamento próprio da matemática moderna. Os pressupostos positivistas consideravam que somente poderia ser científico aquilo que fosse passível de quantificação e que a ciência deveria desconfiar de toda evidência advinda da experiência e do senso comum. 
Dessa forma, a matemática forneceria à ciência moderna,

não só o instrumento privilegiado de análise, como também a lógica da investigação, como ainda o modelo de representação da própria estrutura da matéria. [...] Deste lugar central da matemática na ciência moderna derivam duas consequências principais. Em primeiro lugar, conhecer significa quantificar. [...] Em segundo lugar, o método científico assenta na redução da complexidade. (SANTOS, 1987, p. 4-5).

Entretanto, essa perspectiva de conhecimento começou a ser questionada e a perder sua hegemonia, não somente pelas limitações impostas à prática científica e às possibilidades de interpretação da realidade, mas também em virtude do fato de que, diante da pretensão de tornar-se uma epistemologia totalizante, transformou-se institucionalmente numa prática autoritária, excludente e discriminatória, desconsiderando outras lógicas de pensamento pautadas em princípios, inclusive, contrários ao positivismo e à racionalidade lógico-matemática imposta.

Para autores como Bogdan e Taylor (1987), tais questionamentos contribuíram com o surgimento da denominada "pesquisa qualitativa" no final do século XIX e início do século XX na Europa, e obtiveram um significativo sucesso entre antropólogos e sociólogos, os quais começaram a sentir dificuldades para interpretar a realidade seguindo a lógica positivista, motivo pelo qual começaram a abordar a realidade utilizando-se de fundamentos epistemológicos de natureza qualitativa.

Entretanto, ainda no entendimento de Taylor e Bogdan (1987), os defensores da pesquisa positivista continuaram a fazer profundos questionamentos às técnicas utilizadas no campo da pesquisa qualitativa durante toda a década de 1950, o que dificultou, de alguma forma, o desenvolvimento dessa abordagem do conhecimento até as décadas de 1960 e 1970, quando as abordagens qualitativas foram retomadas fazendo sérias críticas à pretensão de objetividade e neutralidade imposta pela abordagem positivista. Nesse contexto, ocorreu a publicação de uma série de estudos relacionados com a coleta e interpretação de dados qualitativos em diversas áreas das ciências humanas, incluindo o campo da linguística.

Como resultado dessa trajetória histórica da ciência, observa-se, dentre outros aspectos, não um rompimento, mas uma ampliação das metodologias de observação e análise da realidade humana e social ${ }^{1}$.

\footnotetext{
${ }^{1}$ Nesse sentido, concordamos com Silva (1999), para quem a pesquisa qualitativa não inaugurou um novo paradigma de investigação em ciências humanas e sociais, mas trouxe um enfoque diferenciado quanto à natureza da sua abordagem. O que ocorreu foi, na verdade, uma ampliação significativa do alcance do conhecimento em relação ao seu valor, significação e representação, assim como também a necessidade de se admitir que, tanto na prática da pesquisa, para manter o status quo, quanto naquela destinada à transformação da realidade, o que houve foi, de fato, uma mudança de perspectiva que somente dependeria da leitura, ou melhor, da concepção de mundo em que se alinharia cada investigador.
} 
Acerca disso, Santos (1987, p. 7) explicitou ainda que:

O comportamento humano, ao contrário dos fenômenos naturais, não pode ser descrito e muito menos explicado com base nas suas características exteriores e objetiváveis, uma vez que o mesmo ato externo pode corresponder a sentidos de ação muito diferentes. A ciência social será sempre uma ciência subjetiva e não objetiva como as ciências naturais; tem de compreender os fenômenos sociais a partir das atitudes mentais e do sentido que os agentes conferem as suas ações, para o que é necessário utilizar métodos de investigação e mesmo critérios epistemológicos diferentes dos correntes nas ciências naturais, métodos qualitativos ao invés de quantitativos, com vista à obtenção de um conhecimento intersubjetivo, descritivo e compreensivo, em vez de um conhecimento objetivo, explicativo e nomotético.

Nesse contexto, a importância de as pesquisas em ciências humanas e sociais contarem com abordagens adequadas às suas especificidades passou a ser aceita e reconhecida, sobretudo em razão da necessidade de compreensão de questões sociais complexas que surgem ou se intensificam com o modo de produção capitalista, tal como ocorre, por exemplo, no campo dos estudos em políticas educacionais, o qual, uma vez instituído, vem procurando consolidar-se por meio da organização de grupos e linhas de pesquisa no âmbito da pós-graduação, seguido da realização de eventos e de um número expressivo de pesquisas publicadas em revistas especializadas da área.

Nesse sentido, pesquisadores que definiram como objeto de investigação a consolidação desse campo de estudo², tais como Tello e Almeida (2013), Masson (2013) e Souza (2003), apontam a necessidade de se questionar como as pesquisas de tal campo estão sendo produzidas em termos epistemológicos, analíticos e metodológicos.

Acerca disso, Souza (2003) observou que, apesar do constante crescimento no número de trabalhos sobre políticas educacionais, ainda há certa escassez quanto à acumulação de conhecimentos na área. Tello e Almeida (2013, p. 18) concordam afirmando que:

Devemos assinalar que é um campo emergente, no entanto não teve uma quantidade suficiente de estudos que se situam dentro do campo. Têm-se desenvolvido algumas reflexões ou conjecturas teórico-conceituais sobre algumas das questões que propomos neste campo. Contudo, as mesmas não têm sido sistematizadas.

Por outro lado, os mesmos autores apontam a necessidade de os pesquisadores em políticas educacionais contarem com referenciais analíticos e teóricos

\footnotetext{
${ }^{2}$ Tello e Almeida (2013) definem a categoria "campo de estudo" como sendo um espaço teórico, com uma finalidade teórica de análise.
} 
mais consistentes, considerando a dificuldade que muitos deles apresentam para se posicionar epistemologicamente. Do mesmo modo, Masson (2013) observou que, especificamente na América Latina, o campo de estudo das políticas educacionais "ainda é um campo em construção, considerando que as investigações carecem de referenciais analíticos consistentes e uma definição mais clara do objeto de investigação" (MASSON, 2013, p. 56).

Nesse contexto, consideramos ainda a análise de Triviños (1987), que identifica e critica, nas pesquisas em ciências sociais, a predominância de um certo "ecletismo" em relação às correntes epistemológicas, associando esse fato àquilo que denomina de "fraqueza intelectual". Para o autor, os trabalhos científicos que utilizam diferentes correntes de pensamento, por vezes divergentes, sem situá-las de forma adequada e sem identificar suas aproximações e distanciamentos são evidências desse ecletismo. Tello e Almeida (2013) consideram que, nesse aspecto, a explicitação dos referenciais epistemológicos do pesquisador fica descaracterizada e inconsistente.

Parte das dificuldades apresentadas pelos pesquisadores para se posicionarem epistemologicamente, segundo Triviños (1987), é resultado de uma formação acadêmica unilateral, que não permite a construção de uma visão epistemológica ampliada e não oferece subsídios para a criatividade no desenvolvimento dos estudos.

Tendo em vista esses aspectos, o presente artigo se propõe a discutir algumas questões epistemológicas e metodológicas relacionadas ao positivismo, ao materialismo dialético e à fenomenologia, tomando como ponto de partida três categorias utilizadas por Tello e Almeida (2013):

a. perspectiva epistemológica: compreendida como sendo a cosmovisão ${ }^{3}$ assumida pelo pesquisador, que lhe dá as diretrizes para desvelar o objeto de estudo. As perspectivas epistemológicas que serão abordadas neste artigo são o positivismo, o materialismo histórico-dialético e a fenomenologia;

b. posicionamento epistemológico: é o posicionamento político e ideológico do pesquisador, que pode se dar por meio de um posicionamento neoliberal, crítico-analítico, humanista, economicista, dentre outros;

c. enfoque epistemetodológico: refere-se às metodologias utilizadas na pesquisa, sendo que Tello e Almeida (2013) preferem criar o novo termo em vez de utilizar simplesmente "metodológico", a fim de evidenciar que a escolha metodológica não é neutra, ao contrário, está intimamente ligada à perspectiva e ao posicionamento epistemológico, que lhe dão suporte.

\footnotetext{
3 "Conjunto de presuposiciones (o premissas) que sostenemos acerca de la constitución básica de nuestro mundo” (SIRE, 2004, p. 17 apud TELLO; ALMEIDA, 2013).
} 
Com base nessas categorias, passamos a abordar alguns aspectos que consideramos importantes para os investigadores de políticas educacionais, defendendo a necessidade de que estes, ao apresentar suas opções epistemológicas, o façam com coerência e segurança, a fim de contribuir para que o conhecimento produzido seja consistente, confiável e relevante.

\section{Perspectiva epistemológica: breves considerações sobre positivismo, a fenomenologia e o materialismo dialético}

O positivismo, que para Comte, seu fundador, seria o terceiro estado do pensar humano, depois do teológico e do metafísico, é uma tendência dentro do idealismo ${ }^{4}$ filosófico, para o qual as ideias precedem a matéria, sendo essa - o que vem primeiro, a matéria ou as ideias? - uma das questões mais importantes a serem respondidas pela Filosofia.

Sendo assim, as pesquisas de caráter positivista consideram que o real (material) se constrói tendo como base a consciência dos sujeitos de suas experiências, sensações e ideias. Além disso, não se constitui uma prioridade conhecer as causas dos fenômenos, mas sim explicá-los e descobrir, por meio de métodos de verificação/experimentação e análise de dados (métodos essencialmente quantitativos), a relação entre eles.

Para os pesquisadores dessa corrente epistemológica, a sociedade, assim como a natureza, seria regida por leis que independem da vontade e da ação humana, assim, não teria o pesquisador responsabilidades em relação àquilo que sua pesquisa produz, afinal, sua ação, visto que advinda de um ser humano, não teria o poder de influenciar essas leis imutáveis descobertas por meio da ciência. O pesquisador deveria ser o que Tello e Almeida (2013) chamaram de "cabeça vazia", ou seja, um investigador que se considere uma tábula rasa ao iniciar sua pesquisa, sem julgamentos, valores e ideologias.

O positivismo começa a perder espaço nas ciências sociais a partir da década de 70 , quando os cursos de pós-graduação, principalmente, passaram a considerar que seu fazer científico se encontrava "amarrado" a atividades mecânicas distantes das necessidades reais da sociedade. Especialmente em relação às pesquisas sobre políticas, ressaltamos que:

Após essa fase positivista, na qual os problemas e as questões da análise de políticas eram vistos como predominantemente técnicos, a partir dos anos 1980, surgiram críticas aos modelos lineares e às tendências tecnicistas de análise de políticas. (MAINARDES; FERREIRA; TELLO, 2011, p. 153).

\footnotetext{
${ }^{4}$ Segundo Gramsci (1978), o conceito de ideologia ganha importância no século XVIII, significando "ciência das ideias".
} 
Nesse contexto, não necessariamente de forma linear, ganha importância o enfoque fenomenológico, que também se apresenta como uma vertente do idealismo filosófico e, dentro deste, do que foi chamado de idealismo subjetivo, por considerar a subjetividade dos sujeitos ${ }^{5}$. Teve como importante representante o filósofo Husserl, embora outros pensadores tenham sido referência nessa corrente filosófica, tais como Sartre, Merleau-Ponty e Ricoeur. "Como ocorreu com o positivismo, também, dentro da fenomenologia, podemos assinalar "grupos de pensadores" que apresentam suas próprias peculiaridades, introduzindo mudanças no pensamento original da fenomenologia" (TRIVIÑOS, 1987, p. 42).

Para a fenomenologia, que será melhor discutida no decorrer deste trabalho, deve-se descrever a essência das coisas, mas sem se importar a fundo com questões culturais e históricas. É necessário isolar totalmente o objeto de pesquisa, a fim de que possa ser compreendido em sua pureza. Especialmente nos países menos desenvolvidos, essa corrente foi muito debatida, tendo em vista que alguns fenômenos sociais só poderiam ser explicados retomando seu desenvolvimento cultural, social e econômico (TRIVIÑOS, 1987).

Considerando a influência desses aspectos, por vezes negligenciados nas pesquisas de cunho positivista ou fenomenológico, emerge o materialismo dialético ${ }^{6}$, constituindo uma das cinco fases ${ }^{7}$ do materialismo filosófico, que considera, ao contrário do idealismo filosófico, que a matéria precede o espírito e que, assim, a ciência é fruto da produção material do homem. Sobre o materialismo dialético:

Podemos dizer que [...] reconhece como essência do mundo a matéria que, de acordo com as leis do movimento, se transforma, que a matéria é anterior à consciência e que a realidade objetiva e suas leis são cognoscíveis. (TRIVIÑOS, 1987, p. 23).

Para o filósofo do pensamento dialético materialista, Gramsci (1978), a concepção positivista e a materialista dialética divergem em relação aos resultados das pesquisas, pois enquanto para o positivismo a ciência busca encontrar princípios e leis imutáveis, para o materialismo dialético a ciência compreende movimentos contínuos e seus resultados são sempre passíveis de questionamentos.

\footnotetext{
5 “O idealismo filosófico subjetivo, especialmente, tem tido que enfrentar o problema do conhecimento quando este se considera válido exclusivamente para o sujeito. Nenhum sistema filosófico pretende que suas formulações tenham valor só para o sujeito que faz as afirmações sobre os objetos, fenômenos, etc. Toda filosofia procura elaborar verdades de caráter objetivo, isto é, válidas para todos.” (TRIVIÑOS,1987, p. 45).

${ }^{6}$ Seus principais representantes são Marx e Engels.

${ }^{7}$ São cinco as fases do materialismo filosófico: materialismo ingênuo, materialismo espontâneo, materialismo mecanicista, materialismo vulgar e materialismo dialético. Os quatro primeiros materialismos não evoluíram por se apoiarem em raízes metafísicas. Já o materialismo dialético vem evoluindo à medida que se desenvolve o pensamento científico.
} 
Se as verdades científicas fossem definitivas, a ciência teria deixado de existir como tal, como investigação, como novas experiências, reduzindo-se a atividade científica à repetição do que já foi descoberto. O que não é verdade, para felicidade da ciência. Mas, se nem mesmo as verdades científicas são definitivas e peremptórias, também a ciência é uma categoria histórica, um movimento em contínua evolução. (GRAMSCI, 1978, p. 70).

Tello e Almeida (2013, p. 239) acrescentam:

Gramsci compreendia a partir das relações marxistas a importância do intelectual orgânico diferente do intelectual tradicional no contexto do século XX onde nascia a importância da superação de um intelectual elitizado que se considerava uma classe independente, escondido atrás de uma neutralidade científica e alheio às contradições de seu tempo. Por assim dizer, o intelectual orgânico é impelido a se definir e tomar partido ante os conflitos da história.

Assim, como resultado do meio de produção material e das relações sociais do pesquisador, o materialismo dialético não considera haver neutralidade na pesquisa, defendendo que ela deve ser capaz de trazer contribuições para a realidade por meio de sua análise crítica. Para Masson (2013, p. 61), "é nesse sentido que é possível afirmar que não há neutralidade na produção do conhecimento, pois todo processo que envolve o conhecimento está atrelado ao intercâmbio material dos homens". Segundo essa corrente de pensamento, ao investigador não cabe apenas descobrir como os fenômenos acontecem, a fim de, após observá-los, quantificá-los e torná-los previsíveis por meio de leis. Segundo Caetano e Passos (2012), Marx defendeu um conhecimento crítico, mas prático, que implicasse subsídios para a transformação da realidade.

Com esta orientação, o pesquisador assume maior liberdade de eleição de um curso de ação ou de um método determinado, mas paralelamente, maior na responsabilidade (pessoal e profissional) pelas consequências de seu proceder e pelo valor social dos resultados de suas pesquisas. (TELLO; ALMEIDA, 2013, p. 17).

Masson (2013) acrescenta quanto à teoria de Marx:

Não há uma proposição epistemológica dissociada da objetividade do real, pois as idéias não são abstrações "desencarnadas". A opção por trabalhar com esta perspectiva teórica não é apenas uma definição meramente epistemológica, pois deve estar coerente com a visão de mundo do investigador e com o seu compromisso político pela transformação do real. (MASSON, 2013, p. 59, grifo do autor).

O pesquisador de políticas educacionais precisa considerar essas questões, pois fica evidente que sua perspectiva epistemológica refere-se ao seu próprio papel como pesquisador e à postura que deve adotar quanto ao conhecimento 
que ele produz. Nesse aspecto, Tello (2012) defende que à pesquisa científica não cabe o posicionamento neutro, devendo o pesquisador observar como seu trabalho está sendo conduzido, considerando desde a coleta dos dados até a forma de divulgação dos resultados, pois sempre há identificação com alguma perspectiva epistemológica, ainda que involuntariamente. A própria escolha do objeto de pesquisa revela motivações da atividade da consciência do pesquisador, que é sempre cientificamente interessado (MASSON, 2013).

$\mathrm{Al}$ no hacer explícito su posicionamento, las investigaciones que hemos relevado [...] connotan un desarrollo y producción de conocimiento en política educativa desde una posición y perspectiva pseudo-neutral o positivista [...], esto es: llevar a cabo una investigación desde la possibilidade inexistente de la neutralidade y objetividade valorativa [...] La ausencia de posicionamentos explícitos en la investigación en política educativa atenta contra la solidez y coherencia del processo de investigación. (TELLO, 2012, p. 55).

Assim, consideramos ser impossível que a ciência estude fatos apenas para conhecê-los de modo desinteressado, pois a pesquisa sempre serve a um interesse, ainda que isso não fique claro nela. "A questão é como os pesquisadores podem deixar seu compromisso com os valores influenciar sua pesquisa e, ao mesmo tempo, ser escrupulosos em não descobrir simplesmente o que gostariam de encontrar" (GEWIRTZ, CRIBB, 2011, p. 117).

Nesse sentido, o materialismo dialético não vem estabelecer um método de pesquisa $(\mathrm{CHASIN}, 2009)^{8}$, deixando evidente, inclusive, que, sob sua perspectiva, o pesquisador não estabelece nem mesmo as categorias de estudo a priori, pois a investigação parte sempre do real, das relações que os sujeitos estabelecem com o concreto ou material. No entanto, Marx utilizou algumas categorias que auxiliam o pesquisador na compreensão de tais relações, embora se saiba que novas categorias surgem por meio das especificidades de cada pesquisa. Dentre as categorias recorrentes nas obras marxianas, talvez uma das mais importantes seja o "trabalho", condição natural da existência humana. Com base nela é possível inferir que o pesquisador apoiado na perspectiva epistemológica não pode ignorar as relações sociais de produção no contexto capitalista se quiser investigar políticas educacionais.

Caetano e Passos (2012) contribuem com a discussão afirmando que:

O materialismo histórico dialético tem como ponto de partida a produção social da existência (o trabalho) e as relações sociais de produção, constituindose nas categorias básicas definidoras do homem concreto e histórico e no pressuposto do conhecimento. (CAETANO; PASSOS, 2012, p. 20).

\footnotetext{
${ }^{8}$ Caetano e Passos (2012, p. 21) defendem que o materialismo dialético se constitui em um método de análise, ou seja, "uma nova síntese no plano do conhecimento, que se ocupa do concreto e não do abstrato e tem, por isso mesmo, o concreto como ponto de chegada".
} 
Outras categorias como "alienação", "emancipação", "luta de classes", dentre outras, foram levantadas por Masson (2013), sendo importante o aprofundamento no conhecimento destas a fim de que se garanta a consistência dos elementos essenciais às análises subsidiadas pelo materialismo dialético.

\section{Enfoque epistemetodológico: a pesquisa qualitativa e a fenomenologia}

A escolha metodológica está intimamente relacionada à perspectiva epistemológica do pesquisador, daí Tello e Almeida (2013) utilizarem o termo "epistemetodologia", explicitando que tal escolha ultrapassa os limites de uma questão meramente técnica. Um dos maiores desafios enfrentados pelos pesquisadores de políticas educacionais é justamente manter a coerência entre a perspectiva epistemológica e o caminho metodológico percorrido.

$\mathrm{O}$ investigador em educação deve ser um estudioso constante e cauteloso, sabendo que a pesquisa não se faz ou se pensa simplesmente pelo emprego desta ou daquela metodologia ou técnicas específicas, mas através da formação epistemológica do investigador (e esta ao longo de sua vida), que tem um peso substancial no processo da investigação científica. (LIMA, 2010, p. 131).

Considerando tal pressuposto, pretendemos abordar algumas questões relacionadas às pesquisas qualitativas ${ }^{9}$ que podem reconhecer o valor da subjetividade nos processos de análise da realidade, bem como a necessidade de dar vOz aos agentes diretamente envolvidos nos processos de pesquisa, procurando minimizar e até superar o viés da denominada racionalidade instrumental de leitura da realidade, oriunda exclusivamente das percepções, concepções e interpretações dos próprios pesquisadores.

Nesse contexto, queremos inicialmente apontar as diferenças fundamentais entre as abordagens positivista e fenomenológica - já que o materialismo dialético apresenta-se sob outro prisma ideológico, como alternativa a essas duas -, destacando que, enquanto a primeira se limita a pesquisar os fatos ou as causas dos fenômenos sociais, procurando não ser influenciada pelos estados subjetivos individuais, a segunda procura examinar o mundo, preferencialmente o cotidiano, tal como é experienciado, para compreender o comportamento e as ações humanas com base no que cada sujeito ou pequeno grupo social pensa ser a realidade.

A fenomenologia, apesar dos problemas que serão tratados adiante, contribuiu com:

\footnotetext{
${ }^{9}$ As pesquisas qualitativas podem contar com o apoio de técnicas quantitativas, mas isso não é sempre necessário, e abster-se de seu uso não caracteriza a pesquisa como especulativa. Os resultados de pesquisas qualitativas podem se referir a um grupo específico, como também podem alcançar realidades mais amplas, marcadas por traços comuns (TRIVIÑOS, 1987).
} 
a. a introdução dos atores sociais nos ambientes de pesquisa, dando a estes uma função mais ativa e dinâmica, por entender que são capazes de interpretar e interferir nos processos modificadores das estruturas sociais, tornando-se, assim, em vez de meros objetos, sujeitos de pesquisa capazes de contribuir com a descoberta dos diversos sentidos/significados atribuídos à realidade, bem como com a revelação da dinâmica das relações e interações que ocorrem na vida cotidiana;

b. a ampliação do conceito de cultura, que deixou de ser vista como um mero reflexo das forças infraestruturais da sociedade para ser entendida como um sistema de significados que medeiam e influenciam a relação existente entre os indivíduos e as estruturas sociais (infra e supra);

c. a reconceitualização e ressignificação do sentido atribuído ao cotidiano, trazendo para as ciências humanas a realização de estudos relacionados com a vida de pequenas vilas ou cidades, estudos específicos de instituições escolares ou ainda estudos sobre reconstituição familiar, operando a construção do conhecimento por intermédio de um objeto singular no interior de um contexto mais geral (GATTI, 2001).

Nos anos 60, a intelectualidade assistiu ao surgimento dos denominados estudos culturais que, apesar de reconhecerem a importância e a influência da infraestrutura econômica nos destinos da vida humano-social, possibilitaram a realização de estudos mais aprofundados das interações sociais, da subjetividade humana e de suas relações com a superestrutura, tomando como referência a interdependência e o condicionamento mútuo entre ambas as estruturas (SCHAFF, 1995).

Retrospectivamente, o famoso estudo de Edward Thompson, A formação da classe operária inglesa (1963), aparece como um marco na história cultural britânica. Por outro lado, quando foi publicado, o livro recebeu críticas de alguns colegas marxistas pelo que eles chamavam de "culturalismo", ou seja, por colocar ênfase nas experiências e nas idéias, e não nas duras realidades econômicas, sociais e políticas. A reação do autor foi criticar seus críticos pelo "economicismo". Essa tensão entre culturalismo e economicismo foi criativa, pelo menos na ocasião. Encorajou uma crítica interna aos conceitos marxistas centrais de uma fundação econômica e social, ou "base", e uma "superestrutura" cultural. Para Raymond Williams, por exemplo, a fórmula de base e superestrutura era "rígida", e ele preferia estudar o que chamou de "relações entre elementos no modo de vida como um todo". Atraía-lhe a idéia de "hegemonia cultural", ou seja, a sugestão - feita pelo marxista italiano Antônio Gramsci, entre outros - de que as classes dominantes exercem poder não apenas diretamente, pela força e ameaça da força, mas porque suas idéias passam a ser aceitas pelas "classes subalternas". (BURQUE, 2005, p. 37-38). 
Como resultados, continuaram aparecendo (e desaparecendo) contribuições, críticas e divergências decorrentes dos diferentes olhares ontológicos e epistemológicos das várias produções a respeito do estudo histórico-cultural da realidade social.

Baseada nesses aspectos, a pesquisa qualitativa começou uma era de identificação, reconhecimento, descrição e análise das formas de viver de determinados grupos sociais e, em particular, de pessoas ou conjuntos de pessoas vinculados a determinadas instituições sociais, tais como escolas, hospitais, ambientes acadêmicos, comunitários etc. Do mesmo modo, passou a ser utilizada para estudar os fatos e/ou padrões previsíveis (ou mais ou menos previsíveis) do pensamento e do comportamento humano que se manifestam na vida cotidiana, inclusive por meio da instituição de políticas, também sob determinadas condições intersubjetivas e sociais. Tudo isso com a finalidade de desvendar como os espaços institucionais e seus grupos de indivíduos dão sentido simbólico, interpretam e conduzem suas vidas, significando e ressignificando seu cotidiano, sua cultura e suas relações sociais.

No que diz respeito às questões metodológicas relacionadas à pesquisa qualitativa, autores como Lévi-Strauss (1964), Geertz (1989), Alves-Mazzotti e Gewandznajder (2001) parecem ser consensuais ao afirmar que os estudos e análises que envolvem a subjetividade e a intersubjetividade deveriam ser caracterizados, dentre outros aspectos, por longos períodos de observação que ultrapassam, em muitos casos, a periodicidade anual, tempo esse considerado necessário para que os pesquisadores possam compreender e validar os significados dos discursos e das atividades dos grupos que são objeto desse tipo de pesquisa, no qual se inserem, inclusive, as pesquisas sobre políticas educacionais, considerado que estas se encontram permeadas por discursos oficiais e não oficiais advindos daqueles que vivenciam a política, mas que nem sempre conseguem ter "voz".

Procura-se, assim, que os estudos e suas resultantes qualitativas adquiram o status de significativamente representativos quando relacionados com determinados grupos, fenômenos ou eventos sociais.

Discutir os caminhos metodológicos das pesquisas de cunho qualitativo é extremamente importante para os investigadores de políticas educacionais, tendo em vista a tendência crescente de dar voz aos sujeitos que participam da formulação e implementação dessas políticas, bem como aos que são "receptores" delas. Sendo assim, passamos à análise crítica das pesquisas qualitativas que não observam aspectos históricos, sociais e ideológicos em suas análises. 


\section{Dificuldades metodológicas e epistemológicas apontadas no uso de abordagens qualitativas que desconsideram as condições históricas, sociais e ideológicas}

Henry Giroux (1997), conhecido intelectual no meio educacional, foi explícito ao afirmar que as perspectivas de pesquisas fenomenológicas sofrem de graves deficiências epistemológicas e metodológicas. O motivo central dessas deficiências está relacionado com o fato de que toda percepção subjetiva está dialeticamente relacionada com o mundo social e não simplesmente o espelha como se fosse uma imagem fotográfica. Nesse sentido, a ignorância desse pressuposto epistemológico fundamental torna qualquer pesquisador vítima de um subjetivismo distorcido, semelhante ao idealismo filosófico profundamente criticado por Marx e Engels (2002) na obra Ideologia alemã, dentre outros escritos relacionados, principalmente, aos alicerces ideológicos e políticos contidos nesse tipo de visão de mundo.

Dessa forma, Giroux (1997) afirma que o mundo social é mais do que uma simples constelação de significados. Embora seja possível aceitar que todo indivíduo age sobre sua realidade cotidiana baseado em uma compreensão única, não decorre disso que essa compreensão seja fruto de uma série de criações subjetivas capazes de se constituir em uma variedade infinita de maneiras de pensar e de agir, pois isso caracteriza, em essência, uma prática idealista extremamente subjetivista.

Em outras palavras, isso significa dizer que todos os processos de

[...]subjetivação individual estão sempre articulados com os sistemas de relações sociais; portanto, têm um momento de expressão no nível individual, e um outro no nível social, ambos gerando conseqüências diferentes, que se integram em dois sistemas da própria tensão recíproca em que coexistem, que são a subjetividade social e a individual. A subjetividade social não é abstração, é o resultado de processos de significação e sentido que caracterizam todos os cenários de constituição da vida social, e que delimitam e sustentam os espaços sociais em que vivem os indivíduos, por meio da própria perpetuação dos significados e sentidos que os caracterizam dentro do sistema de relações em que eles atuam e se desenvolvem. (REY, 2003, p. 207).

Baseando-se nesses aspectos, várias são as limitações e críticas feitas às pesquisas realizadas com perspectivas qualitativas, especialmente as pesquisas do campo de estudo das políticas educacionais, que buscam estudar os sentidos atribuídos às falas, aos discursos, aos conteúdos ou às representações dos indivíduos advindos de sua experiência na formulação ou implementação de políticas, sem considerar todo um contexto social, econômico e cultural que os circunda. 
Em virtude do viés idealista-subjetivista contido em determinadas matrizes metodológicas, tal como a fenomenologia, em muitos casos essas perspectivas aproximam-se muito da metodologia neoempirista da ciência positivista, ainda que defendam a ideia da necessária participação e da necessidade de dar vOz aos atores sociais. Tal aproximação transparece quando os sentidos atribuídos pelos sujeitos de pesquisa são utilizados nessas abordagens como "fatos de palavras" ou dados empíricos válidos, porém com a diferença de que tais dados são cientificamente reconhecidos, independentemente do número de amostras utilizadas para:

a. explicar microrrealidades cotidianas;

b. confirmar ou refutar teorias elaboradas de acordo com valores ou princípios predeterminados; justificar/demonstrar/refutar hipóteses de pesquisa; ou

c. questionar os resultados de pesquisas ou construções teóricas oriundas de abordagens epistemologicamente diferentes das utilizadas nesse tipo de estudos.

Em resumo, corre-se o risco de tornar idealista-subjetivista toda a pesquisa, que ao se concentrar exclusivamente no nível micro das relações humanas, utiliza a produção de sentido dos atores sociais, deixando de:

a. ilustrar como os arranjos sociopolíticos e ideológicos influenciam, limitam e condicionam historicamente a atribuição individual e coletiva dos sentidos que se referem a determinados fenômenos sociais ou a significados e saberes que se constroem no mundo da experiência cotidiana, os quais podem desempenhar importantes papeis nos processos de estruturação (ou, inclusive, desestruturação) da própria tessitura da vida em sociedade;

b. elucidar como as estruturas sociais e políticas mascaram a realidade e promovem a hegemonia ideológica (GIROUX, 1997);

c. explicar como os indivíduos atribuem sentido a determinados fenômenos e como surgem diferentes variedades de significados e saberes, todos oriundos da vida cotidiana;

d. explicitar como esses mesmos discursos são capazes de se sustentar diante do impacto da subjetividade social, o que inclui a ideologia reinante no âmbito supraestrutural de toda comunidade/sociedade.

Para pesquisadores como Berger (2004) e Rey (2003), a forma com que as percepções, atitudes e crenças são construídas socialmente e situadas em meios culturais específicos significa, em essência, aceitar a ideia ingênua de que as 
relações sociais e o poder subjacente, que dão forma e modelagem aos acordos institucionais, são algo natural, normal e inevitavelmente instituído ${ }^{10}$. Esse tipo de leitura e construção simbólica da realidade social, associado à falta de referências filosóficas e epistemológicas consistentes, que permitam a compreensão de como, por que ou o que está ocorrendo nos "mundos cotidianos" alvos, limita profundamente tanto as oportunidades de reflexão pelos indivíduos quanto a sua capacidade de organização e inovação no interior das estruturas sociais em que eles mesmos se encontram inseridos.

$\mathrm{Na}$ atualidade, tanto se ampliou a pesquisa qualitativa com as perspectivas acima apontadas que hoje nela tudo passou a caber, desde "os folclores, os sensos comuns, os relatos de experiência (de preferência a própria), para não computar os desabafos emocionais" (WARDE, 2000, p. 70). Isso lembrando que a dificuldade atual de se definir o que pode e o que não pode ser considerado pesquisa foi fruto das questões inicialmente apontadas em relação à conceituação de ciência e de metodologia científica, resultantes da crítica ao paradigma da racionalidade instrumental e, em especial, à abordagem positivista de ciência.

Ao analisar o impacto das pesquisas científicas e criticar a falta de fundamentação teórica presente em inúmeras delas, Alves-Mazzotti (2003) afirma que, independentemente de se argumentar que diferentes paradigmas debatem entre si quanto à utilização de teorias a priori, nem mesmo os teóricos construcionistas, por exemplo, afetos a esse tipo de construção de conhecimento, defendem sua ausência no produto final, uma vez que sugerem que o pesquisador construa sua teorização com base nos dados obtidos. Nesse sentido, a autora alerta, não sem preocupação, que

[...] muitas pesquisas, sob a alegação de "dar voz" aos sujeitos ou de valorizar as práticas, tem-se limitado a reproduzir falas e falas dos sujeitos, sem qualquer tentativa de identificar regularidades, relações e categorias ou se servir de um instrumental analítico capaz de organizar e dar sentido aos dados. A crescente valorização da subjetividade parece estar levando a uma reificação do sujeito, em detrimento da teorização e do diálogo com os autores que já se ocuparam do tema. Aparentemente, para fugir ao equívoco de encarar a teoria como verdade, cai-se no equívoco de transferir para os sujeitos a posse da verdade. (ALVES-MAZZOT'TI, 2003, p. 37).

\footnotetext{
${ }^{10}$ Premissa idealista surgida na cosmologia do século XVIII, planejada e colocada em prática para controlar as colônias e disciplinar o indivíduo nos Estados nascentes, nos processos ideológicos de busca de regras universais sobre a evolução humana, capaz de justificar um tipo de desenvolvimento social considerado cíclico, mas com uma estrutura de regulamentação social vista como puramente administrativa.
} 
Dar voz aos sujeitos que foram de alguma forma silenciados será de pouca valia se não se procura compreender, por exemplo, como e por que essas vozes foram silenciadas. A compreensão das subjetividades requer, assim, que se busque relacioná-las às condições sociais em que foram produzidas, procurando ir além da mera descrição e contribuindo para a acumulação do conhecimento (ALVES-MAZZOTTI, 2003). Dessa forma, consideramos que não basta ao pesquisador do campo de estudos em políticas educacionais analisar os discursos e falas dos sujeitos que têm relação com essas políticas, fazendo-se necessário contextualizá-las nos movimentos históricos, políticos, econômicos, culturais e sociais.

Ao analisar essas dificuldades apontadas no contexto da produção de conhecimento utilizando-se de pesquisas qualitativas, especialmente as do campo de estudo das políticas educacionais que, por vezes, desconsideram os fundamentos epistemológicos e as teorias mais amplas subjacentes à produção de sentido advindo dos atores envolvidos nas políticas investigadas, alertamos para o perigo de se cair em um relativismo científico, fazendo com que as pesquisas deixem de contribuir para a construção de conhecimentos suficientemente relevantes e confiáveis para orientar as próprias políticas e práticas em educação.

Seguindo uma linha muito parecida de pensamento, Soriano (2004) é explícito ao afirmar que diante dos grandes problemas que afetam os países subdesenvolvidos e da manutenção de estruturas e instituições socioeconômicas e políticas obsoletas, "é preciso que se faça uma reflexão profunda sobre a finalidade das ciências sociais” (SORIANO, 2004, p. 13).

Para esse autor, diante do atual contexto mundial, as alternativas que se apresentam aos cientistas sociais consistem em fazer pesquisas:

a. comprometidas com os grupos sociais mais necessitados de mudanças estruturais no sistema socioeconômico;

b. orientadas para a mera especulação;

c. colocadas a serviço das organizações privadas que controlam boa parte da produção e distribuição de bens e serviços;

d. realizadas em função de objetivos econômicos individuais: ingressar ou continuar em algum sistema de estímulo à produtividade acadêmica. (SORIANO, 2004, p. 14-15).

Frente a tais perspectivas de pesquisa, o autor menciona que aqueles que optam pelo primeiro caminho concordam que é imperativo conhecer direta e profundamente os problemas sociais relacionados ao objeto de pesquisa, a fim de descobrir as suas causas e poder contribuir, de forma mais realista, para a sua análise crítica e possível superação. Ele destaca que para isso deve-se considerar a "necessidade de superar a superficialidade ou inconsistência teórico- 
metodológica com que se fazem muitas pesquisas" (Ibid., p.15), concordando com o que temos defendido desde o início do artigo.

Nesse sentido, a tomada de consciência das contribuições e das limitações das perspectivas epistemológicas e dos enfoques epistemetodológicos torna-se fundamental para ressaltar que a construção do conhecimento implica a possibilidade dialética de ampliação da capacidade de reflexão do pesquisador e, politicamente, sugere a necessidade de que ele assuma coerentemente qual o projeto de sociedade que defende, podendo considerar as quatro alternativas acima citadas por Soriano (2004).

Conforme debatido, a primeira delas está associada, necessariamente, a uma concepção e prática relacionadas diretamente com os movimentos e organizações sociais que lutam para mudar o atual modelo de sociedade, pretendendo provocar mudanças estruturais no sistema socioeconômico.

A segunda, muito ligada àqueles intelectuais que, na perspectiva de Gramsci, tornaram-se autônomos como profissionais, está acima dos ideais de classe e de sociedade que defendem. A terceira e a quarta encontram-se, além de relacionadas com a segunda alternativa, associadas, em grande parte, à defesa de interesses que, em essência, contribuem com a manutenção das atuais condições de vida, interessadas na preservação do status quo, ainda que nos seus discursos os pesquisadores sustentem que estão contribuindo para o desenvolvimento e o progresso social, principalmente em virtude do fato de que muitos defensores históricos de outros projetos de sociedade não dispõem de uma proposta concreta de transformação social.

Dessa forma, além de reconhecer algumas motivações que podem conduzir à elaboração de pesquisas, cabe mencionar que tais motivações refletem não somente a concepção de mundo e de intelectual que perpassa a vida do pesquisador como pessoa e profissional, mas também, e fundamentalmente, o projeto histórico que este assume, epistemologicamente fundamentado ou não, decorrendo disso a escolha pela perspectiva epistemológica e metodológica utilizada, podendo estar alicerçada na fenomenologia, no positivismo, no materialismo dialético ou em outra corrente.

Nesse sentido, Ball (2011) traz importantes contribuições observando que os pesquisadores não deveriam analisar as políticas, por exemplo, isolando-as, deixando de fazer relações importantes com outras políticas e outros contextos. Pesquisas orientadas pelo materialismo dialético, por exemplo, precisam considerar tais relações, buscando articular as políticas educacionais com a dimensão macroeconômica e com outras políticas setoriais, programas e projetos, além de estudar o contexto de formulação e implementação dessas políticas (NETTTO, 2003 apud MASSON, 2013, p. 70). 
Assim, entendemos que a metodologia utilizada na pesquisa em políticas educacionais precisa estabelecer relações entre o objeto de estudo e a realidade social, a fim de que o conhecimento produzido possa dar sua contribuição. Sem tal observância, o pesquisador corre o risco de, ainda que bem intencionado, investir seus esforços em realizar pesquisas algumas vezes com metodologias trabalhosas e complexas, como é o caso das pesquisas qualitativas que utilizam entrevistas, grupos focais, dentre outros, que não produzem conhecimentos válidos para a sociedade e a academia.

\section{Posicionamento epistemológico: o pesquisador diante do mundo e da ciência}

O posicionamento epistemológico tem a ver com a concepção de mundo do pesquisador e com suas motivações, conforme explicitado anteriormente. Posicionar-se epistemologicamente, para Tello e Almeida (2013), diz respeito, também, à neutralidade ou à pseudoneutralidade que possui, ou intenta possuir, o pesquisador.

Gewirtz e Cribb (2011) abordam a questão com base no lugar que se dá aos valores ${ }^{11}$ na pesquisa, defendendo que o investigador precisa tomar todo o cuidado para que seus valores não determinem a maneira como a pesquisa será realizada, nem tampouco os resultados dela ou a forma de coletar e analisar os dados. Os autores não acreditam que seja possível separar o pesquisador do cidadão comprometido com as maneiras pelas quais o conhecimento produzido será utilizado. "Eles (pesquisadores) fazem parte do mundo que estão pesquisando, e o trabalho de pesquisa está inevitavelmente ligado a inúmeras escolhas éticas e políticas" (GEWIRTZ; CRIBB, 2011, p. 108).

Isso não significa que o pesquisador pode se posicionar e deixar que seus valores manipulem os resultados da pesquisa. Pelo contrário, o posicionamento epistemológico norteia as interpretações e adjetiva a perspectiva epistemológica, mas nunca força a pesquisa a um fim desejado.

Neste sentido o posicionamento epistemológico se converte no posicionamento político e ideológico do pesquisador. Podemos mencionar posicionamentos neoinstitucionais, institucionalistas, clássico ou jurídico-legal, construtivismo político, da complexidade, ecletismo, pós-moderno, pós-modernista, hiperglobalista, estético, neoliberal, enfoque transformador, funcionalista, crítico, crítico-radical, crítico-analítico, teóricos da resistência, crítico reproductivista, humanista, economicista, etc. O posicionamento epistemológico repousa sobre a seleção que realiza o investigador enquanto a perspectiva epistemológica com a que desenvolverá o pesquisador. Estes posicionamen-

\footnotetext{
${ }^{11}$ Estes envolvem julgamentos éticos, crenças, intenções e visões de mundo.
} 
tos são a adjetivação das perspectivas epistemológicas. (TELLO; ALMEIDA, 2013, p. 14).

Conforme citado, muitas são as formas de enxergar o mundo e o valor das pesquisas em políticas educacionais, tendo em vista que, de acordo com seu posicionamento diante do mundo e da própria ciência, o pesquisador contribui para a transformação ou manutenção do status quo da sociedade, por isso, mais importante que tentar manter-se neutro - partindo da concepção de que isso não é possível - é ser ético e deixar claro, tanto quanto possível, os valores sociais, políticos e ideológicos que perpassam a pesquisa. Cabe ressaltar aqui a importância de que o pesquisador conheça as possibilidades epistemológicas e epistemetodológicas existentes, sendo capaz de avaliar suas contribuições e limitações para a pesquisa, a fim de sentir-se seguro para defender suas escolhas perante aqueles que discordem de seu posicionamento. Tal segurança refere-se, inclusive, à necessidade de assumir responsabilidades pelas implicações dos resultados da pesquisa.

O pesquisador em políticas educacionais precisa ser crítico em relação às contribuições que seu trabalho pode trazer para a compreensão e a avaliação das políticas implementadas, sabendo que, embora não seja possível fazer previsões e prescrições, a pesquisa sempre aponta para alguma possibilidade.

A pesquisa educacional como diálogo deve muito mais do que produzir conhecimento científico pelo conhecimento científico acerca da educação, deve preocupar-se também e principalmente, dentro de seu agir comunicativo, em desbravar caminhos que possibilitem benefícios à comunidade científica, à sociedade e mui especialmente à educação. (LIMA, 2010, p. 131).

Os resultados da pesquisa têm impactos no contexto político e social em que se insere o pesquisador, havendo lutas políticas e ideológicas pelos sentidos de tais resultados, por isso a necessidade de se abandonar uma visão "inocente" de ciência e de se posicionar em relação ao projeto de sociedade que se quer construir.

\section{Considerações finais}

A articulação coerente entre perspectiva epistemológica, posicionamento epistemológico e enfoque epistemetodológico (ou metodológico) é de suma importância para que o pesquisador possa construir sua pesquisa garantindo a coerência e a cientificidade necessárias a ela. No entanto, acreditamos que seja difícil posicionar-se frente às diversas correntes de pensamento sem um mínimo de conhecimento acerca das limitações e possibilidades que cada uma pode proporcionar para o desvelamento do objeto de pesquisa. É claro que dificilmente o 
pesquisador poderá conhecer a fundo todas essas possibilidades, tampouco este artigo intenta fazê-lo, no entanto, é preciso seriedade e disciplina para situar a pesquisa, epistemológica e metodologicamente, de maneira coerente e segura, a fim de que as contribuições do trabalho sejam reais. Além disso, um posicionamento epistemológico claro pode cercar as possibilidades de uso indevido dos resultados obtidos na pesquisa.

Entendemos que atualmente alguns fatores têm contribuído para certa dificuldade dos pesquisadores em se posicionar, dentre eles está o "produtivismo" imposto por agências de fomento à pesquisa, que tem obrigado muitos pesquisadores a trocarem qualidade por quantidade de trabalhos produzidos. A esse aspecto, associa-se o curto tempo destinado às pesquisas em nível de pós-graduação stricto sensu, por exemplo, considerando que os pesquisadores que chegam a esses programas são cada vez mais jovens, não tendo tido ainda, em muitos casos, tempo de amadurecer suas concepções epistemológicas, analíticas e metodológicas de pesquisa.

Assim, o pesquisador de políticas educacionais precisa superar tais dificuldades, procurando conhecer os diferentes pontos de observação da realidade, as formas de dar "voz" aos sujeitos de pesquisa, os caminhos para a análise dos dados e divulgação dos resultados, atentando para a impossibilidade de neutralidade, a responsabilidade para com as implicações da pesquisa e a preocupação em contextualizar o objeto de estudo no tempo e no espaço, considerando as relações que ele estabelece. As políticas educacionais têm um tempo e um espaço de formulação, de implementação e de fazer sentir seus efeitos, e isso precisa ser reconhecido para que a pesquisa não se precipite em conclusões e prescrições, considerando que sua contribuição pode ser válida no momento presente, mas em relação ao futuro a ciência, em uma perspectiva materialista dialética, não faz previsões. A ciência "reduz o que o homem não conhece a um empírico 'não conhecimento' que não exclui a cognoscibilidade, mas a condiciona ao desenvolvimento dos instrumentos físicos e ao desenvolvimento da inteligência histórica dos cientistas individuais" (GRAMSCI, 1987, p. 70, grifo do autor).

Acrescentamos que essa articulação do objeto de pesquisa com os elementos que o circundam, seja sob espectro histórico, temporal, espacial ou outro, traz um olhar e um conhecimento mais aprofundados sobre esse objeto, demonstrando que as políticas públicas não se constituem repentinamente por meio das subjetividades de pessoas, mas são resultado de todo um movimento econômico, social, cultural e histórico. Do mesmo modo, as representações dos envolvidos na pesquisa, seja por meio de entrevistas, aplicação de questionários etc., não se construíram isoladas desses movimentos, ao contrário, para entender os pontos de vista desses sujeitos é preciso entender de onde eles "falam" e que elementos contribuem para a formação do seu pensamento. Daí destacarmos 
neste artigo algumas críticas que têm sido feitas às pesquisas qualitativas cuja perspectiva epistemológica parte da fenomenologia, que busca compreender o objeto em sua essência. Em contrapartida, discutimos alguns elementos acerca do materialismo dialético, que, resumidamente,

[...] concebe a ciência como resultado da produção de vida material. Esta, por sua vez, condicionando os processos sociais, políticos, econômicos, intelectuais, gera as condições materiais necessárias ao desenvolvimento do conhecimento humano e suas diversas formas de representação. (LIMA, 2010, p. 113).

Desta feita intentamos avançar um pouco mais, discutindo a importância de estudos voltados para as questões epistemológicas e metodológicas das pesquisas em políticas educacionais, a fim de contribuir para o fortalecimento do campo de estudos em questão e de fornecer subsídios para a reflexão de pesquisadores da área.

\section{Referências}

ALVES-MAZZOTTI, A. J.; GEWANDZNAJDER, F. O método nas ciências naturais e sociais: pesquisa quantitativa e qualitativa. São Paulo: Pioneira, 2001.

ALVES-MAZZOTTI A. J. Impacto da pesquisa educacional sobre as práticas educacionais. In: ZAGO, N.; CARVALHO, M. P. de; VILELA, R. A. T. (Org.). Itinerários de pesquisa: perspectivas qualitativas em Sociologia da Educação. Rio de Janeiro: DP\&A, 2003. p. 33-48.

BALL, S. J. Sociologia das políticas educacionais e pesquisa crítico-social: uma revisão pessoal das políticas educacionais e da pesquisa em política educacional. In: BALL, S. J.; MAINARDES, J. (Org.). Políticas educacionais: questões e dilemas. São Paulo: Cortez, 2011. p. 21-53.

BALL, S. J.; MAINARDES, J. Políticas educacionais: questões e dilemas. São Paulo: Cortez, 2011.

BERGER, P. Modernidade, pluralidade e crise do sentido. São Paulo: Vozes, 2004.

BOGDAN, R.; TAYLOR, S. J. Introduccíon a los métodos cualitativos de investigación. Buenos Aires: Paidos, 1987.

BURQUE, P. O que é história cultural? Rio de Janeiro: Zahar, 2005.

CAETANO, E.; PASSOS, L. A. Modernidade e o (des) conhecimento do mundo: Marx e Merleau-Ponty. In: KASSAR, M. C. M.; SILVA, F. C. T. (Org.). Educação e pesquisa no centro-oeste: políticas públicas e desafios na formação humana. Campo Grande: Editora UFMS, 2012. p. 17-32.

CHASIN, J. Marx: estatuto ontológico e resolução metodológica. São Paulo: Boitempo, 2009.

GATTI, G. C. do V. História e representações sociais da escola estadual de Uberlândia (1929-1950). 2001. 131 f. Dissertação (Mestrado em Educação) - Faculdade de Educação, Universidade Federal de Uberlândia, Uberlândia, 2001. 
GEERTZ, C. A interpretação das culturas. Rio de Janeiro: LTC, 1989.

GEWIRTZ, S.; CRIBB, A. O que fazer a respeito de valores na pesquisa social: o caso da reflexividade ética na sociologia da educação. In: BALL, S. J.; MAINARDES, J. (Org.). Políticas educacionais: questões e dilemas. São Paulo: Cortez, 2011. p. 100-122.

GIROUX, H. A. Os professores como intelectuais: rumo a uma pedagogia crítica da aprendizagem. Porto Alegre: Artmed, 1997.

GRAMSCI, A. Concepção dialética da história. 3. ed. Rio de Janeiro: Civilização brasileira, 1978.

LÉVI-STRAUSS, C. Tristes trópicos. São Paulo: Companhia das Letras, 2000.

LIMA, P. G. Ciência e epistemologia: reflexões necessárias à pesquisa educacional. Quaestio: Revista de Estudos em Educação, Sorocaba, v. 12, n. 2, p. 109-138, nov. 2010.

MAINARDES, J.; FERREIRA, M. dos S.; TELLO, C. Análise de políticas: fundamentos e principais debates teórico-metodológicos. In: BALL, S. J.; MAINARDES, J. (Org.). Políticas educacionais: questões e dilemas. São Paulo: Cortez, 2011. p. 143-172.

MASSON, G. Orientações para o desenvolvimento de investigação em políticas educativas a partir da teoria marxista. In: TELLO, C.; ALMEIDA, M. de L. P. de. (Org.). Estudos epistemológicos no campo da pesquisa em política educacional. Campinas: Mercado de Letras, 2013. p. 55-76.

MARX, K.; ENGELS, F. A ideologia alemã. São Paulo: Centauro: 2002.

REY, F. G. Sujeito e subjetividade. São Paulo: Pioneira, 2003.

SCHAFF, A. A sociedade informática. São Paulo: Unesp brasiliense, 1995.

SANTOS, B. de S. Um discurso sobre as ciências. 7. ed. Porto: Edições Afrontamento, 1987.

SILVA, M. A. Os contrapontos da produção acadêmica na emergência da pesquisa qualitativa. Educativa, Goiânia, v. 12, n. 1, p. 163-170, jan./jun. 2009.

SORIANO, R. R. Manual de pesquisa social. Petrópolis: Vozes, 2004.

SOUZA, C. "Estado do campo" da pesquisa em políticas públicas no Brasil. Revista Brasileira de Ciências Sociais, São Paulo, v. 18, n. 51, p. 15-20, fev. 2003. DOI: 10.1590/ S0102-69092003000100003

TARDIF, M. Saberes profissionais dos professores e conhecimentos universitários: elementos para uma epistemologia da prática profissional dos professores e suas consequências em relação à formação para o magistério. Revista Brasileira de Educação, Rio de Janeiro, n. 13, p. 05-24, 2000.

TELLO, C. G. Las epistemologias de la política educativa: vigilancia y posicionamiento epistemológico del investigador en política educativa. Práxis Educativa, Ponta Grossa, v. 7, n. 1, p. 53-68, jan./jun. 2012. DOI: 10.5212 /PraxEduc.v.7i1.0003

TELLO, C.; ALMEIDA, M. de L. P. de. Estudos epistemológicos no campo da pesquisa em política educacional. Campinas: Mercado de Letras, 2013. 
TRIVIÑOS, A. N. S. Introdução à pesquisa em ciências sociais: a pesquisa qualitativa em educação. São Paulo: Atlas, 1987.

Recebido em 29/11/2013

Versão final recebida em 25/03/204

Aceito em 05/04/2014 